\title{
The prognostic utility of GRACE risk score in predictive cardiovascular event rate in STEMI patients with successful fibrinolysis and delay intervention in non PCl-capable hospital: a retrospective cohort study
}

\author{
Yotsawee Chotechuang ${ }^{1,2}$, Arintaya Phrommintikul ${ }^{3 *}$, Roungtiva Muenpa ${ }^{4}$, Jayanton Patumanond ${ }^{5}$,
} Tuanchai Chaichuen ${ }^{6}$, Srun Kuanprasert ${ }^{3}$, Noparat Thanachikun ${ }^{3}$, Thanawat Benjanuwatra ${ }^{3}$ and Apichard Sukonthasarn ${ }^{3}$

\begin{abstract}
Background: Fibrinolytic therapy is the main reperfusion therapy for most STEMI patients in several countries. Current practice guidelines recommended routine early pharmacoinvasive (within 3-24 h after successful fibrinolysis, however it cannot be performed in timely fashion due to limitation of PCl-capable hospitals. This study aimed to evaluate the prognostic utility of the GRACE score in patients receiving delayed intervention after successful fibrinolysis in non PCl-capable hospital.

Methods: We retrospectively analysed the data from the Maharaj Nakorn Chiang Mai Hospital acute ST-elevation myocardial infarction (STEMI) registry during the period 2007-2012. The STEMI patients who had successfully fibrionolysis in non PCl-capable hospital and received delayed PCl (during $24 \mathrm{~h}$ to 14 days after successful fibrinolytic therapy) at Maharaj Nakorn Chiang Mai hospital were included. The primary end point for this analysis was the composite outcomes, which included all-cause mortality, re-hospitalization with acute coronary syndrome (ACS), re-hospitalization with heart failure (HF) and stroke at 1 and 6-month.

Results: A total of 152 patients were included. 88 patients and 64 patients were in low GRACE group (GRACE risk score $\leq 125$ ) and intermediate to high GRACE group (GRACE risk score above 126), respectively. The median time from fibrinolysis to coronary intervention in low GRACE group was 8.5 days (interquartile range, 4.6-10.9) and 7.9 days (interquartile range,3.2,12.0) in intermediate to high GRACE group $(p=0.482)$. At 1 month, the composite cardiovascular outcome at 1 month occurred in 2 patients (2.3\%) in low GRACE group and 10 patients (15.6\%) in intermediate to high GRACE group ( $P=0.003$ ). During 6 months, the composite cardiovascular outcomes occurred in 6 patients $(6.8 \%)$ in low GRACE group and 12 patients $(18.7 \%)$ in intermediate to high GRACE group $(P=0.024)$. The cumulative of composite cardiovascular outcome was significant higher in intermediate to high GRACE group than in low GRACE group (Hazard ratio: $2.97,95 \% \mathrm{Cl} 1.11-7.90 ; p=0.030)$.

(Continued on next page)
\end{abstract}

\footnotetext{
* Correspondence: arintaya.p@cmu.ac.th

${ }^{3}$ Cardiology Division, Department of Internal Medicine, Faculty of Medicine,

Chiang Mai University, Chiang Mai 50200, Thailand

Full list of author information is available at the end of the article
} 
(Continued from previous page)

Conclusion: The long delay pharmacoinvasive strategy in intermediate to high GRACE score after successful fibrinolysis in non PCl-capable facilities were associated with worse cardiovascular outcomes than the patients with low GRACE score at 1 and 6 months. GRACE risk score may be helpful and guided the clinicians in non PCl-capable center in early transferred to early intervention in STEMI patients after fibrinolytic therapy.

Keywords: GRACE risk score, STEMI patients with successfully fibrinolysis, Delay pharmacoinvasive strategy

\section{Background}

Primary percutaneous coronary intervention (PPCI) is preferred reperfusion therapy for acute ST-elevation myocardial infarction (STEMI). However, the PCI-capable center is still limited in several countries including Thailand. Therefore, fibrinolytic therapy is the main reperfusion therapy for most STEMI patients in our country. Current practice guidelines recommended routine coronary angiogram (CAG) after successful fibrinolysis, the so called pharmacoinvasive strategy [1-5]. However, early pharmacoinvasive (within 3-24 h after successful fibrinolysis) cannot be performed in a timely fashion due to limitation of PCI-capable hospitals. Previous acute coronary syndrome (ACS) registries, Thailand Registry in Acute Coronary Syndrome (TRACS) showed a low rate of coronary angiography and intervention during index admission and referral centers for early pharmacoinvasive strategy are still limited [6]. Therefore, risk stratification and identify risk of the patients are important in non PCI-capable hospital. Patients with intermediate to high risk for adverse cardiovascular event should be transferred for coronary angiogram as soon as possible. Although several risk scores for acute coronary syndrome (ACS) have been developed for stratified risk of ACS patients, GRACE (Global Registry of Acute Coronary Events) score is developed to focus on clinical risk assessment and to improve the selection of patients for clinical and interventional procedures following an ACS episode [7]. Many studies and meta-analysis demonstrated the accuracy and the usefulness of the GRACE score on the mortality of ACS patients in hospital and follow-up after hospital discharged [8-13]. This study aimed to evaluate the prognostic utility of the GRACE score in patients receiving delayed intervention after successful fibrinolysis.

\section{Methods}

\section{Study design and population}

We retrospectively analysed the data from the Maharaj Nakorn Chiang Mai Hospital STEMI registry during the period 2007-2012. The STEMI patients who had successfully fibrinolysis in non PCI-capable hospital and received delayed coronary intervention (during $24 \mathrm{~h}$ to 14 days after successful fibrinolytic therapy) at Maharaj Nakorn Chiang Mai hospital were included for analysis in the study. The exclusion criteria were the patients who unsuccessfully fibrinolysis (ST-segment decrease in elevation less than $50 \%$ at $90 \mathrm{~min}$ after fibrinolysis), received early coronary intervention $(<24 \quad \mathrm{~h}$ after fibrinolytic therapy), received very delayed coronary intervention ( $>2$ weeks after fibrinolytic therapy), the patients who denied for further interventions after fibrinolysis, the patients who received primary PCI or rescue PCI and the patients who had the previous history of coronary-artery bypass surgery. The protocol design was approved by the local institutional Research Ethics Committees of Faculty of Medicine, Chiang Mai University and Lampang hospital.

The data were collected from the medical recorded by the researcher. Demographic characteristics, medical history, presenting symptoms, baseline GRACE score time from symptom onset to administration fibrinolytic therapy, time from fibrinolysis to percutaneous coronary intervention, coronary intervention procedure and clinical outcomes were collected for analysis. In the patients who did not visit to the hospital to follow up, the telephone call was used to interview for evaluating the clinical outcomes.

\section{Definitions and end points}

The STEMI was defined as the presence of at least $0.1-\mathrm{mV}$ ST-segment elevation or new or presumably new left bundle branch block with elevation of cardiac enzyme levels above the reference range. Successfully fibrinolysis means the ST-segment decrease in elevation $\geq 50 \%$ (partial resolution) and $\geq 70 \%$ (complete resolution) at $90 \mathrm{~min}$ after fibrinolysis. Delayed coronary intervention means coronary intervention, including coronary angiogram and percutaneous coronary intervention performed during $24 \mathrm{~h}$ to 14 days after successfully fibrinolysis. The GRACE score composed of medical history (age, history of congestive heart failure, and history of myocardial infarction), findings at initial presentation (resting heart rate, systolic blood pressure, and ST-segment depression), and findings during hospitalization (initial serum creatinine, elevation of cardiac enzyme, and no in-hospital PCI), the total score range from $0-258$ points. The patients were stratified into low (GRACE risk score <126), intermediate to high risk group (GRACE risk score $\geq 126$ ). The primary end point for this analysis was composite outcomes, which included all-cause mortality, re-hospitalization with 
ACS, re-hospitalization with heart failure (HF) and stroke at 1 and 6-month. Re-hospitalized with ACS was defined as re-admission after discharge from hospital with ACS composed with clinical chest pain, rising of cardiac enzymes and dynamic ST-segment change. Re-hospitalized with heart failure was defined as re-admission after discharge from hospital with clinical decompensated heart failure or received intravenous diuretic. Culprit vessel PCI was defined as PCI confined to culprit vessel lesion only. The multivessel PCI was defined as PCI in which lesions in the culprit vessel as well as $\geq 1$ non-culprit vessel lesions.

\section{Statistical analysis}

Baseline demographics, procedural and angiographic characteristics presented with continuous measures and are expressed as mean \pm standard deviation (SD) or median and interquartile range (IQR) wherever appropriate. The categorical data are expressed as number (percentages), except where indicated. Differences in continuous variables were analyzed with the Student's $t$ test or Wilcoxon rank-sum tests. The categorical variables were analyzed with Chi-square test and Fisher's exact test. A $P$-value $<0.05$ was considered statistically significant. Composite endpoints and other clinical outcomes will be expressed as number (percentages). The prognostic utility of GRACE score on clinical outcomes was analyzed by logistic regression analysis and presented as odd ratio and area under the ROC curve (AuROC). The composite outcome was analyzed by use time to event analysis and presented with Kaplan-Meier curve. We conducted statistical analyses using Stata version 13 (Stata corporation, College Station, TX). The sample size was calculated by base on the data of the previous study of Yan et al. [14] reported death/myocardial re-infarction at 30 days in the standard treatment was $8.1 \%$ and estimated $5 \%$ loss of follow-up. To achieve a power of $80 \%$, with a type- 1 error probability of $5 \%$ (two-sided), allowable of estimated error (margin error) was $5 \%, 120$ patients were needed in this study.

\section{Results}

\section{Baseline clinical characteristics}

Among 3171 STEMI patients during study period, 2045 STEMI patients received fibrinolytic therapy and a total of 152 patients met inclusion criteria, as shown in Fig. 1. Eighty-eight patients and 64 patients were in low GRACE group (GRACE risk score $\leq 125)$ and intermediate to high GRACE group (GRACE risk score above 126), respectively. The 6-month follow-up was available in $97 \%$ of the patients in both groups. The clinical characteristics were shown in Table 1 . The median time from fibrinolysis to coronary intervention in low GRACE group was 8.5 days (interquartile range, 4.6-10.9) and
7.9 days (interquartile range,3.2,12.0) in intermediate to high GRACE group $(p=0.482)$ (Additional file 1).

\section{Angiographic findings, procedural details and complications of the procedure}

Angiographic findings and procedural details were presented in Table 2. Double vessel disease and triple vessel disease presented in 45.5 and $65.6 \%$ in low GRACE group and intermediate to high GRACE group respectively. Lesion type $\mathrm{B} 2$ and $\mathrm{C}$ presented in 44.6 and $53.8 \%$ in low GRACE group and intermediate to high GRACE group respectively. Sixty-three percent $(N=56)$ of the patients in low GRACE group and $61 \%(N=39)$ of the patients in intermediate to high GRACE group underwent PCI $(P=0.738)$ while $36 \%$ of the patients in low GRACE group $(N=32)$ and $39 \%$ of the patients in intermediate to high GRACE group $(N=25)$ had only coronary angiography $(p=0.738)$. Culprit vessel PCI was performed in $89 \%(N=50)$ of the patients in low GRACE group and $92 \%(N=36)$ of the patients in intermediate to high GRACE group $(=0.733)$. Among the patients underwent PCI, $76.8 \%(N=43)$ of the patients in low GRACE group and $76.3 \%(N=29)$ of the patients in intermediate to high GRACE group received drug-eluting stent (DES). The complications during and post procedure were shown in Table 3.

\section{Clinical outcomes}

At 1 month, the composite cardiovascular outcome at 1 month occurred in 2 patients $(2.3 \%)$ in low GRACE group and 10 patients $(15.6 \%)$ in intermediate to high GRACE group $(P=0.003)$. During 6 months, the composite cardiovascular outcomes occurred in 6 patients $(6.8 \%)$ in low GRACE group and 12 patients $(18.7 \%)$ in intermediate to high GRACE group $(p=0.024)$ (Table 4$)$. There was no death in hospital in low GRACE group when 2 patients ( $3.1 \%)$ in intermediate to high GRACE group died $(P=0.176)$. Rate of re-hospitalized with HF at 1 and 6 months were significantly higher in intermediate to high GRACE group than low GRACE group (9.4 \% vs $1.1 \%, p=0.022$ and $10.9 \%$ vs $2.3 \%, p=0.036$, respectively).

\section{The GRACE score and clinical outcomes}

The composite cardiovascular outcome and re-hospitalized with $\mathrm{HF}$ at 6 months were higher in intermediate to high GRACE group than in the low GRACE group (OR: 3.20 , $95 \%$ CI: $1.13-9.06 ; P=0.029$ and OR: $5.34,95 \% \mathrm{CI}$ : $1.07-26.68 ; P=0.041$ respectively). The cumulative of composite cardiovascular outcome was significant higher in intermediate to high GRACE group than in low GRACE group (Hazard ratio: $2.97,95 \%$ CI 1.11-7.90; $P=0.030$ ), as shown in Fig. 2. We analysed the prognostic utility of GRACE score on clinical outcomes by the evidence from 


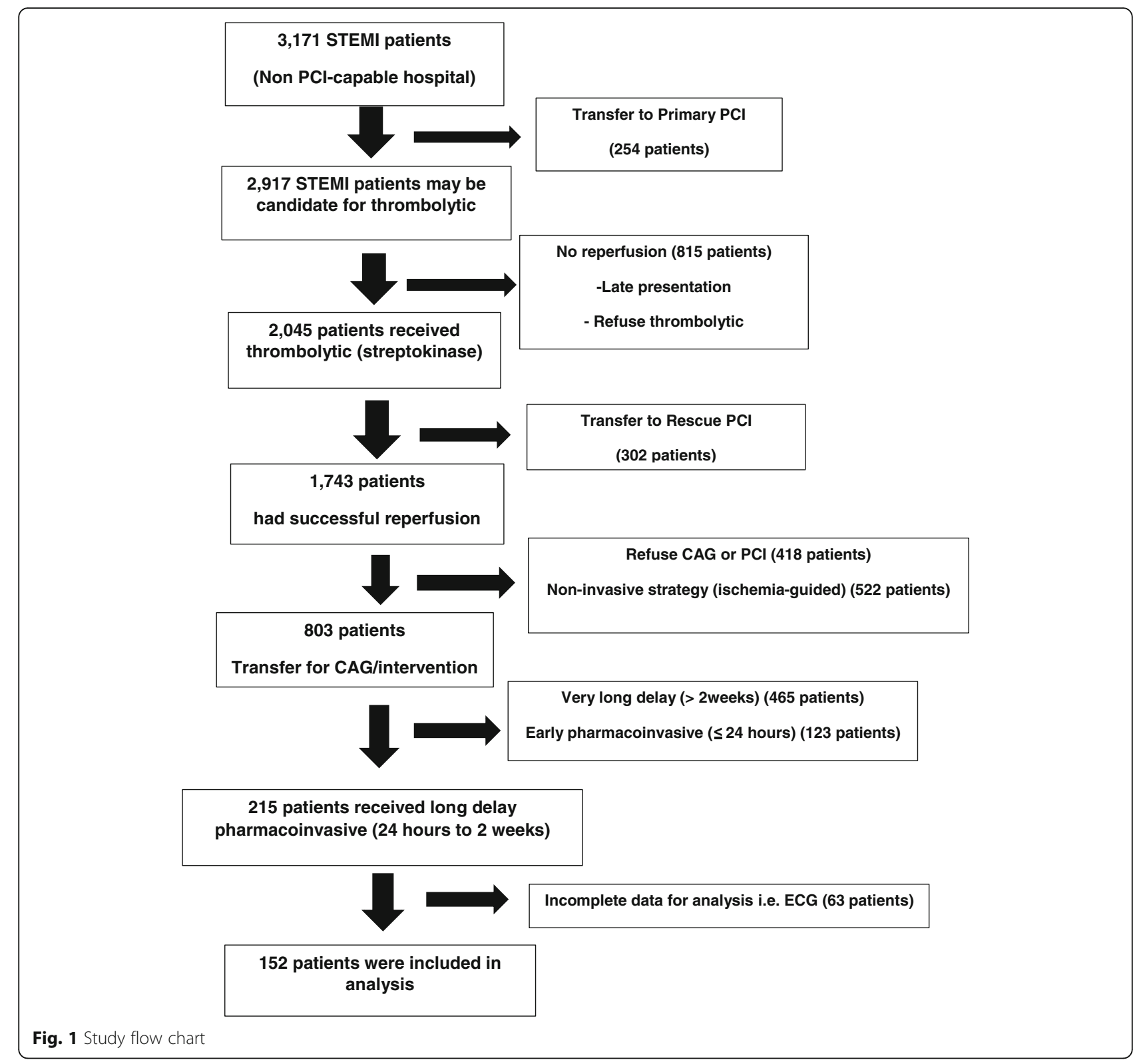

the area under the ROC curve. The area under the ROC (AuROC) of GRACE score for 6-month cardiovascular death was 0.794 (95\% CI 0.75-0.83). The AuROC of composite cardiovascular outcomes was 0.641 (95\% CI 0.52-0.76), as shown in Fig. 3.

\section{Discussion}

Although early pharmacoinvasive strategy (within 3-24 h) after successful reperfusion are recommended by several guidelines [1-5], timely fashion CAG is not widely available in countries with limited PCI capable hospitals including Thailand. Several randomized trials and meta-analysis have shown that early routine postthrombolysis angiography with subsequent PCI reduced the rates of re-infarction and recurrent ischemia compared with a watchful waiting strategy, in which angiography and revascularization were indicated only in the patients with spontaneous or induced severe ischemia or left ventricular (LV) dysfunction $[15,16]$. The benefits of early routine PCI after thrombolysis were seen in the absence of increased risk of adverse events in many studies $[15,16]$. The data from TRACS showed only half $(50 \%)$ of STEMI patients performed CAG on index admission. Fibrinolysis (especially streptokinase), is the first choice for treatment in low risk STEMI patients ( $42.6 \%$ of STEMI patients received streptokinase and $1 \%$ received Tenecteptase) [6]. Because of only one cardiac catheterization (during the period 2007-2012) in Northern Thailand (Maharaj Nakorn Chiang Mai Catheterization laboratory), the 
Table 1 Baseline clinical characteristics of patients according to GRACE risk score $(n=152)$

\begin{tabular}{|c|c|c|c|}
\hline Clinical characteristics & $\begin{array}{l}\text { Low GRACE } \\
\text { group }(N=88)\end{array}$ & $\begin{array}{l}\text { Intermediate } \\
\text { to high GRACE } \\
\text { group }(N=64)\end{array}$ & $P$-value \\
\hline Age (years), mean $\pm S D$ & $55.3 \pm 8.5$ & $67.7 \pm 3.2$ & $<0.001$ \\
\hline Gender, (\%) & & & 0.696 \\
\hline Male & $55(62.5)$ & $38(59.4)$ & \\
\hline Female & $33(37.5)$ & $26(40.6)$ & \\
\hline $\begin{array}{l}\text { Time from symptoms } \\
\text { onset to fibrinolysis, } \\
\text { median (hours) } \\
\text { (IQR:25th,75th percentile) }\end{array}$ & 2.7 (IQR: 2,3.8) & 2.8 (IQR: 2,4.5) & 0.347 \\
\hline $\begin{array}{l}\text { Time from fibrinolysis to } \\
\text { CAG or PCI median (days) } \\
\text { (IQR:25th,75th percentile) }\end{array}$ & 8.5 (IQR:4.6,10.9) & 7.9 (IQR: $3.2,12.0)$ & 0.482 \\
\hline GRACE score, mean \pm SD & $100.2 \pm 15.7$ & $142.2 \pm 13.4$ & $<0.001$ \\
\hline LVEF (\%) & $54.9 \pm 10.6$ & $52.5 \pm 13.6$ & 0.239 \\
\hline \multicolumn{4}{|c|}{ Preexisting medical conditions, n (\%) } \\
\hline Diabetes & $18(20.4)$ & $10.6(15.6)$ & 0.448 \\
\hline Hypertension & $39(44.3)$ & $27(42.2)$ & 0.794 \\
\hline Dyslipidemia & $30(34.1)$ & $16(25.0)$ & 0.228 \\
\hline Smoking & $50(56.8)$ & $34(53.1)$ & 0.651 \\
\hline Chronic kidney disease & $3(3.4)$ & $3(4.7)$ & 0.681 \\
\hline
\end{tabular}

geographic and long distance of transfer and few of number of interventional cardiologists, primary PCI and early routine PCI after successful fibrinolysis were very difficult for this situation. Rescue PCI or primary PCI were performed in the patients who failed fibrinolytic therapy or cardiogenic shock at presentation. Hence, most of the STEMI patients in Thailand, especially in Northern of Thailand who successfully fibrinolytic therapy received the long delay coronary intervention (more than $24 \mathrm{~h}$ after fibrinolysis) and some of them received elective $\mathrm{PCI}$ or very long delayed intervention or elective PCI (after 2 weeks from successful fibrinolytic therapy) [6]. Several studies demonstrated the worst cardiovascular outcomes in the patients who received delay coronary intervention after thrombolysis [15-21]. The Southwest German Interventional Study in Acute Myocardial infarction (SIAM III) evaluated the effects of transfer early PCI (within $6 \mathrm{~h}$ after fibrinolysis) compared with delay PCI strategy (elective PCI 2 weeks after fibrinolysis) [17]. The early PCI showed significant reduction of primary end point (death, re-infarction, target lesion revascularization (TLR) and ischemic events) (HR: $0.61 ; 95 \%$ CI $0.42-0.88, p=0.008$ ) and higher long term survival than delayed PCI $(p=0.057)$ [17]. Similarly to The Trial of Routine Angioplasty and Stenting after Fibrinolysis to Enhance Reperfusion in Acute Myocardial Infarction (TRANSFER-AMI) trial, showed that the patients who transfer from non-PCI
Table 2 Angiographic findings and procedural details $(n=152)$

\begin{tabular}{|c|c|c|c|}
\hline $\begin{array}{l}\text { Angiographic findings } \\
\text { and procedural details }\end{array}$ & $\begin{array}{l}\text { Low GRACE } \\
\text { group }(N=88)\end{array}$ & $\begin{array}{l}\text { Intermediate to high } \\
\text { GRACE group }(N=64)\end{array}$ & $P$-value \\
\hline \multicolumn{4}{|c|}{ Angiographic findings, n (\%) } \\
\hline Mild disease & $9(10.2)$ & $1(1.6)$ & 0.045 \\
\hline Single vessel disease & $39(44.3)$ & $21(32.8)$ & 0.180 \\
\hline Double vessel disease & $24(27.3)$ & $22(34.4)$ & 0.375 \\
\hline Triple vessel disease & $16(18.2)$ & $20(31.2)$ & 0.082 \\
\hline \multicolumn{4}{|c|}{ Lesions (according to ACC/AHA), n (\%) } \\
\hline Type A & $14(25.0)$ & $7(18.0)$ & 0.461 \\
\hline Type B1 & $17(30.4)$ & $11(28.2)$ & 0.503 \\
\hline Type B2 & $17(30.4)$ & $10(25.6)$ & 0.651 \\
\hline Type C & $8(14.2)$ & $11(28.2)$ & 0.120 \\
\hline \multicolumn{4}{|l|}{ Procedural performed } \\
\hline $\begin{array}{l}\text { CAG without PCl, } \\
\text { n (\%) }\end{array}$ & $32(36.4)$ & $25(39.1)$ & 0.738 \\
\hline Medical treatment & $26(81.2)$ & $15(60.0)$ & 0.136 \\
\hline CABG & $6(18.8)$ & $10(40.0)$ & 0.136 \\
\hline $\mathrm{PCl}, \mathrm{n}(\%)$ & $56(63.6)$ & $39(60.9)$ & 0.738 \\
\hline Culprit vessel $\mathrm{PCl}$ & $50(89.3)$ & $36(92.3)$ & 0.733 \\
\hline Multivessel PCl & $6(10.7)$ & $3(7.7)$ & 0.733 \\
\hline \multicolumn{4}{|l|}{ Procedural details, n (\%) } \\
\hline POBA & $1(1.8)$ & $6(15.4)$ & 0.018 \\
\hline Thrombus aspiration & $0(0)$ & $3(7.7)$ & 0.066 \\
\hline Bare metal stent & $13(23.2)$ & $5(13.2)$ & 0.290 \\
\hline Drug eluting stent & $43(76.8)$ & $29(76.3)$ & 0.574 \\
\hline
\end{tabular}

Table 3 Complications during and post-procedure $(n=152)$

\begin{tabular}{llll}
\hline Complications & Low GRACE & Intermediate to high & $P$-value \\
& group $(\mathrm{N}=88)$ & GRACE group $(\mathrm{N}=64)$ & \\
\hline During procedure, $\mathrm{n}(\%)$ & & & $\mathrm{NS}$ \\
Abrupt vessel closure & $0(0)$ & $0(0)$ & 0.511 \\
$\begin{array}{l}\text { New thrombus } \\
\text { formation }\end{array}$ & $2(3.57)$ & $0(0)$ & $\mathrm{NS}$ \\
$\begin{array}{l}\text { Side branch occlusion } \\
\text { No reflow }\end{array}$ & $0(0)$ & $0(0)$ & 0.511 \\
$\begin{array}{l}\text { Dissection } \\
\text { Emergency unplanned }\end{array}$ & $0(0)$ & $0(0)$ & 0.589 \\
CABG & $1(1.8)$ & $0(0)$ & $\mathrm{NS}$ \\
Post procedure, $\mathrm{n}(\%)$ & $0(0)$ & $\mathrm{NS}$ \\
$\begin{array}{l}\text { Hematoma } \\
\text { Hematuria }\end{array}$ & $0(0)$ & $0(0)$ & 0.579 \\
$\begin{array}{l}\text { Gastrointestinal } \\
\text { bleeding }\end{array}$ & $0(0)$ & $0(0)$ & $\mathrm{NS}$ \\
$\begin{array}{l}\text { Required blood } \\
\text { transfusion }\end{array}$ & $0(0)$ & $0(0)$ & $\mathrm{NS}$ \\
$\begin{array}{l}\text { Contrast-induced } \\
\text { nephropathy }\end{array}$ & $0(0)$ & $0(0)$ & $\mathrm{NS}$ \\
\hline
\end{tabular}


Table 4 Clinical outcomes at 1 and 6 months of follow-up $(n=152)$

\begin{tabular}{|c|c|c|c|}
\hline Clinical outcomes & $\begin{array}{l}\text { Low GRACE } \\
\text { group }(N=88)\end{array}$ & $\begin{array}{l}\text { Intermediate to high } \\
\text { GRACE group }(N=64)\end{array}$ & $P$-value \\
\hline In-hospital mortality, n (\%) & $0(0)$ & $2(3.1)$ & 0.095 \\
\hline \multicolumn{4}{|l|}{ At 1 month } \\
\hline Composite outcomes & $2(2.3)$ & $10(15.6)$ & 0.003 \\
\hline ACS & $1(1.1)$ & $1(1.6)$ & 0.666 \\
\hline Heart failure & $1(1.1)$ & $6(9.4)$ & 0.022 \\
\hline Stroke & $0(0)$ & $1(1.6)$ & 0.421 \\
\hline CV death & $0(0)$ & $2(3.1)$ & 0.180 \\
\hline Non-CV death & $0(0)$ & $0(0)$ & NS \\
\hline Loss to follow-up & $2(2.3)$ & $2(3.1)$ & 0.562 \\
\hline \multicolumn{4}{|l|}{ At 6 month (cumulative) } \\
\hline Composite outcomes & $6(6.8)$ & $12(18.7)$ & 0.024 \\
\hline ACS & $4(4.5)$ & $1(1.6)$ & 0.298 \\
\hline Heart failure & $2(2.3)$ & $7(10.9)$ & 0.036 \\
\hline Stroke & $0(0)$ & $2(3.1)$ & 0.421 \\
\hline CV death & $0(0)$ & $2(3.1)$ & 0.175 \\
\hline Non-CV death & $0(0)$ & $0(0)$ & NS \\
\hline Loss to follow-up & $2(2.3)$ & $2(3.1)$ & 0.562 \\
\hline
\end{tabular}

center within $6 \mathrm{~h}$ after thrombolysis had fewer ischemic complications than standard treatment (delayed PCI) without increasing of major bleeding [18]. A metaanalysis showed mortality benefit at 30-day and 1 year of the STEMI patients with early transfer PCI after fibrinolysis as compared with ischemic-guided intervention (delayed PCI) [15, 16]. The NORwegian study on District treatment of ST-Elevation Myocardial infarction (NORDISTEMI) study also demonstrated a significant reduction in the composite cardiovascular outcome (death, re-infarction, stroke, or recurrent ischemia) at 1 year in the patients with immediate transferred to PCI following with thrombolysis as compared with the patients in conservative arm treatment (6\% vs $16 \%, p=$ 0.01) [19]. Similarly to The Combined Abciximab RE-teplase Stent Study in Acute Myocardial Infarction (CARESS-AMI) study, a more conservative strategy (i.e. angiogram only in cases of failed thrombolysis) was associated with a worse clinical outcome than the strategy of angiogram and intervention (if indicated) in all cases following thrombolysis (composite of death, re-infarction and refractory ischemia at 30-day, $11 \%$ vs $4 \%, p=0.004$ ) [20]. From the previous data, no studies demonstrated of the benefit in the cardiovascular outcomes of the early and/or delay pharmacoinvasive strategies in STEMI patients who received streptokinase for treatment similar to our study. On the data from CARESS-AMI [20] and TRANSFER-AMI [18], The American College of Cardiology (ACC) and the American heart association (AHA) give a class IIa recommendations for high risk features (such as Kilip class $>2$, extensive ST-elevation, left ventricular ejection fraction (LVEF) $<35 \%$, or hypotension) should be immediate transferred to PCI-capable facilities [3, 4]. The transfer of low and moderate risk STEMI patients to PCI-capable center received a class IIb recommendation. No available data showed the benefit outcome of early transferred for PCI in low and moderate risk patients.

Risk stratification of the STEMI patients were very important for the clinicians in non-PCI capable hospital to use to guide for judged and selected the STEMI patients for early invasive strategy. GRACE risk score, one of clinical risk score, has been shown to be a good risk stratification score in population with STEMI and NSTE-ACS. Several studies demonstrated the validation and the usefulness of GRACE score in stratified the STEMI patients for an early invasive management $(\mathrm{AUC}=0.81 ; 95 \% \mathrm{CI} 0.80-0.82$ for STEMI and $\mathrm{AUC}=0.80 ; 95 \%$ CI $0.74-0.89$ for NSTEACS) [12]. The AuROC of 6-month mortality and the composite cardiovascular outcome of our study were 0.794 (95\% CI 0.75-0.83) and 0.641 (95\% CI 0.52-0.76). From our study, the GRACE score seem to be better performance in the cardiovascular mortality rather than the composite cardiovascular outcome of the patients with long delay pharmacoinvasive as similar as the previous study [12]. But the usefulness of GRACE score for predict the composite cardiovascular outcome is still unclear. A subgroup analysis of TRANSFER-AMI trial revealed the beneficial outcome of early pharmacoinvasive strategy only in patient with a low to intermediate GRACE risk score $(<155)$, while the early invasive strategy was associated with worse outcome in high-risk patients $(\geq 155)$ [14]. The pharmacoinvasive strategy was associated with a lower risk of death/re-MI in the low-intermediate GRACE risk group ( $\mathrm{HR}=0.52$, $95 \%$ CI $0.32-0.86, p=0.010$ ), but a higher risk of death/re-MI in the GRACE high-risk group ( $\mathrm{HR}=1.98,95 \%$ CI 1.06-3.67, $p=0.031)$ [14]. From this subgroup analysis from TRANSFER-AMI, risk score may also guide the best strategy to achieve and maintain myocardial reperfusion after administration of fibrinolytic therapy [14]. Similar to our study, the longer delay pharmacoinvasive strategy $(24 \mathrm{~h}$ to 2 weeks after successful fibrinolysis) in non PCI-capable facilities may associate with the worst of composite cardiovascular outcome (death, re-hospitalized with ACS, re-hospitalized with HF and stroke) at 30-day and 6-month when compared with the patients with low GRACE score ( $15.6 \%$ vs $2.3 \%$ at 30 days, $p=0.003$ and $16.7 \%$ vs $6.8 \%$ at 6 months, $p=0.024)$. Therefore, the patients with intermediate to high GRACE risk score should be early transferred to PCI-capable center after fibrinolytic therapy.

The in-hospital mortality and 6-month mortality of our study was lower than the previous registry (TRACS) because the difference in baseline patient characteristics, the severity of the patients and the number of the 


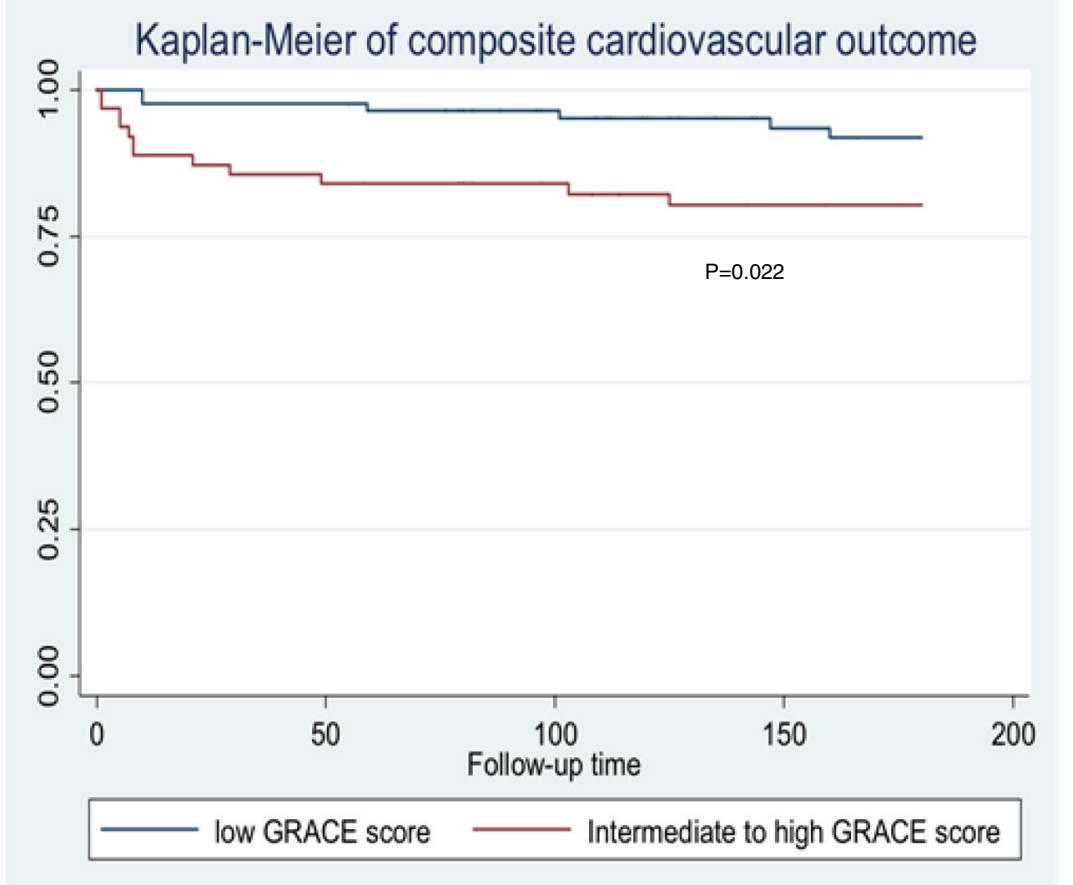

\begin{tabular}{|c|c|c|c|}
\hline Number patients at risk & 0 day & 30 days & 180 days \\
\hline Low GRACE group & 88 & 86 & 82 \\
\hline Intermediate to high GRACE group & 64 & 54 & 52 \\
\hline
\end{tabular}

Fig. 2 Kaplan-Meier of composite cardiovascular outcome

patients received of the percutaneous coronary intervention on admission (in-hospital mortality $5.3 \%$ vs $3.1 \%$ and 6-month mortality $12.1 \%$ vs $3.1 \%$ ) [6]. Most of the patients in our study had multivessel disease but underwent culprit vessel PCI only in significant proportion of patients. A small number of the patients underwent multivessel PCI during index hospitalization (10.7\% in low GRACE group vs $7.7 \%$ in intermediate to high GRACE group). The meta-analysis and systematic review of Moretti et al. [22] in management multivessel coronary disease in STEMI patients, 5855 patients from 6 studies (1 RCT) compared between only culprilt vessel PCI vs complete PCI performed during index hospitalization. No difference in major adverse cardiovascular events (MACE) at short-term (90 days) and long term outcome at 1 year but significant reduced the repeat revascularization at 1 year similar to culprit vessel PCI vs complete revascularization during PCI. The rate of CABG was high especially in intermediate to high GRACE group because of high prevalence of multivessel disease and complex coronary artery disease (Type B2 and C) which may suitable for CABG after acute phase of STEMI. Previous ACS registry in Thailand (TRACS) showed the lower rate of CABG but the revascularization data was collected only in hospital-phase of STEMI [6]. The selective biased in enrolled patients who survived during index admission may contribute to low cardiovascular event in our study. We showed the performance of GRACE score for mortality of in-hospital, short term (30 days) and 6-month Therefore, the GRACE risk score is useful for prediction in short- and long-term mortality of the STEMI patients with successful fibrinolysis and delay intervention in non PCI-capable hospital.

There are some limitations in our study that may compromise clinical implication. Our study was a retrospective observational study (non-randomized). The large number of excluded patients reflected the limited 
A

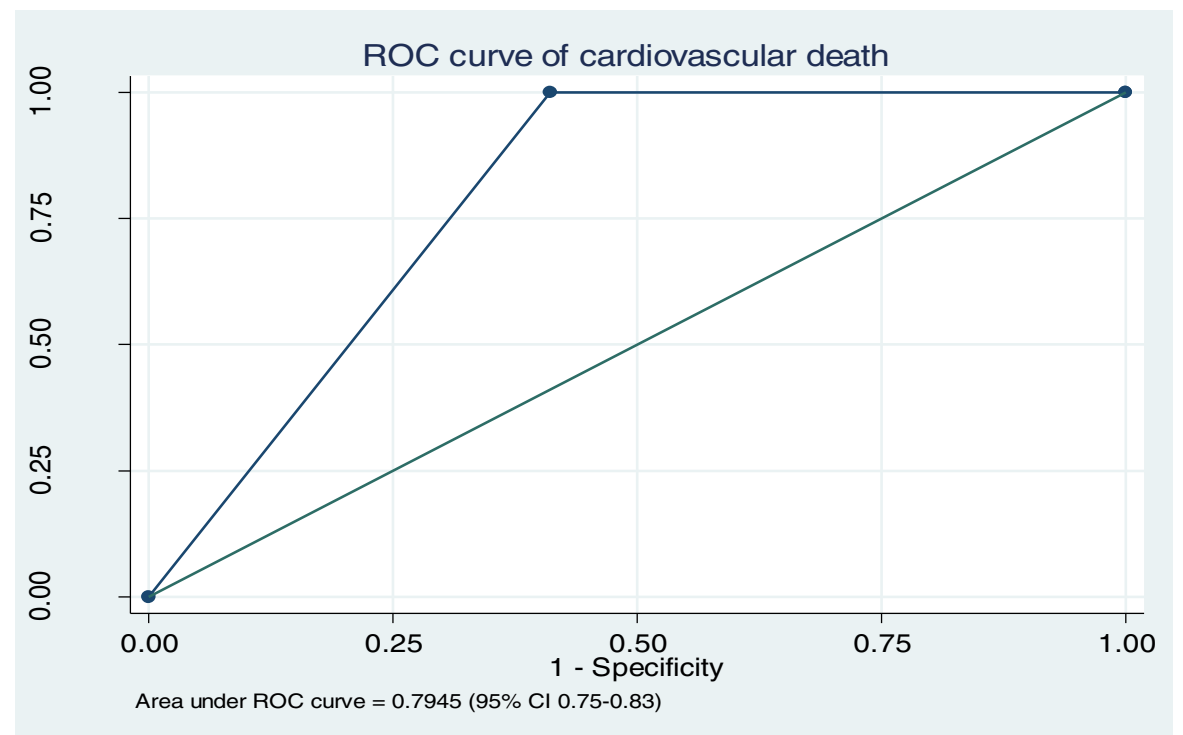

B

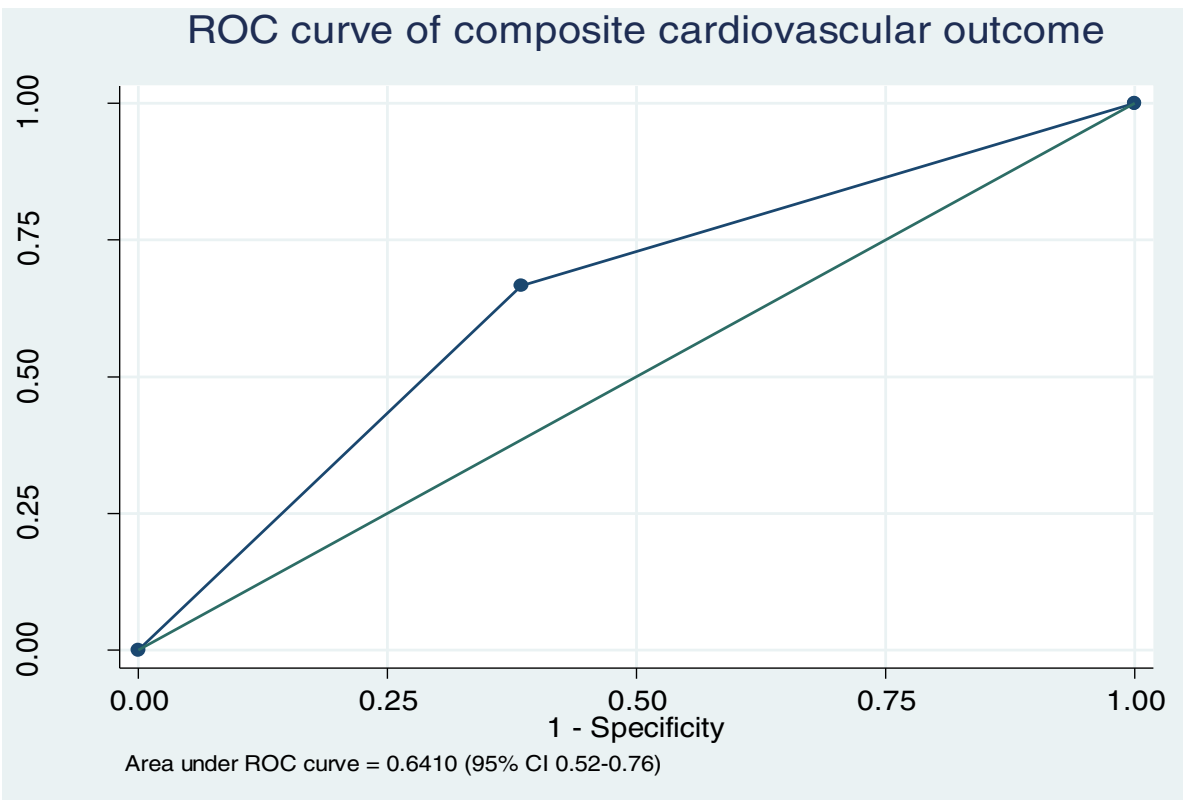

Fig. 3 The Area under the Curve (AuROC) for the performance of GRACE score in predicting cardiovascular event. a 6-month cardiovascular death 6-month cardiovascular death (AuROC $=0.794,95 \% \mathrm{Cl}$ 0.75-0.83). b Composite cardiovascular outcome (AuROC $=0.641,95 \% \mathrm{Cl} 0.52-0.76$ )

accessibility to coronary intervention within 2 weeks. The mortality was lower than the previous study because the small number of patients with high GRACE risk were included in our study.

\section{Conclusion}

The long delay pharmacoinvasive strategy in intermediate to high GRACE score after successful fibrinolysis in non PCI-capable facilities were associated with worse cardiovascular outcomes (death, re-hospitalized with ACS, re-hospitalized with HF and stroke) than the patients with low GRACE score at 30 days and 6 months. GRACE risk score may be helpful and guided the clinicians in non PCI-capable center in early transferred to early intervention in STEMI patients after fibrinolytic therapy. 


\section{Additional file}

Additional file 1: Prognostic value of GRACE. The dataset for the prognostic value of GRACE risk score analysis. (XLSX $52 \mathrm{~kb}$ )

\section{Abbreviations}

ACC: The American College of Cardiology; ACS: Acute coronary syndrome; AHA: The American heart association; AuROC: Area under receiver operating characteristic; BMI: Body mass index; CAG: Coronary angiography; CARESS AMI: The combined abciximab RE-teplase stent study in acute myocardial infarction study; CV: Cardiovascular; GRACE score: The Global Registry for Acute Coronary Events score; HF: Heart failure; IQR: Interquartile range; LVEF: Left ventricular ejection fraction; MACE: Major adverse cardiovascular events; NORDISTEMI: The NORwegian study on District treatment of STElevation Myocardial infarction study; NS: No statistical significant; NSTEACS: Non ST-elevation acute coronary syndrome; PCl: Percutaneous coronary intervention; PPCl: Primary percutaneous coronary intervention; RCT: Randomized control trial; ROC: Receiver operating characteristic; SD: Standard deviation; SIAM III: Southwest German Interventional Study in Acute Myocardial infarction study group; STEMI: ST- elevation myocardial infarction; TLR: Target lesion revascularization; TRACS: Thailand Registry in Acute Coronary Syndrome; TRANSFER-MAI trial: The trial of routine angioplasty and stenting after fibrinolysis to enhance reperfusion in acute myocardial infarction

\section{Acknowledgments}

I would like to special thank all staffs from Cardiology Division, Department of Internal Medicine, Chiang Mai University. I also thank nurses and all administers in Northern Cardiac Center, who always helpful and supported me in data collection.

\section{Funding}

No source of funding were used to conducted this study or prepare this manuscript.

\section{Authors' contributions}

All authors made substantial contributions to conception, design, and drafting the manuscript. YC design study, conducted the data collection, analysis and prepared the manuscript. AP, RM, JP, TC, SK, NT, TB and AS conducted a critical review of the manuscript and provided final editing to the manuscript. All authors read and approved the final manuscript.

\section{Competing interests}

The authors declare that they have no competing interests.

\section{Consent for publication}

Not applicable.

\section{Ethics approval and consent for participate}

The protocol was reviews and approved by the Research Ethics Committee 4, Faculty of Medicine, Chiang Mai University and Research Ethics Committee of Lampang Hospital. The patients' inform consent was waived due to the nature of retrospective study.

\section{Author details}

${ }^{1}$ Clinical Epidemiology Program, Faculty of Medicine, Chiang Mai University, Chiang Mai 50200, Thailand. ${ }^{2}$ Cardiology Division, Internal Medicine Department, Lampang Hospital, Lampang 52000, Thailand. ${ }^{3}$ Cardiology Division, Department of Internal Medicine, Faculty of Medicine, Chiang Mai University, Chiang Mai 50200, Thailand. ${ }^{4}$ Pharmaceutical Care Unit, Pharmacy Department, Lampang Hospital, Lampang 52000, Thailand. ${ }^{5}$ Center of Excellence in Applied Epidemiology, Faculty of Medicine, Thammasat University, Bangkok 12121, Thailand. ${ }^{6}$ Cardiac catheterization laboratory Unit, Maharaj Nakorn Chiang Mai Hospital, Chiang Mai, Thailand50200.

Received: 6 May 2016 Accepted: 22 October 2016 Published online: 08 November 2016

\section{References}

1. Wijns W, Kolh P, Danchin N, Di Mario C, Falk V, Folliguet T, Garg S, Huber K, James S, Knuuti J, Lopez-Sendon J, Marco J, Menicanti L, Ostojic M, Piepoli
MF, Pirlet C, Pomar JL, Reifart N, Ribichini FL, Schalij MJ, Sergeant P, Serruys PW, Silber S, Uva MS, Taggart D. Guidelines on myocardial revascularization. The Task Force on Myocardial Revascularization of the European Society of Cardiology (ESC) and the European Association for Cardio-Thoracic Surgery (EACTS). Developed with the special contribution of the European Association for Percutaneous Cardiovascular Interventions (EAPCI). Eur Heart J. 2010;31:2501-55.

2. Steg PG, James SK, Atar D, Badano LP, Blomstrom-Lundqvist C, Borger MA, Di Mario C, Dickstein K, Ducrocq G, Fernandez-Aviles F, Gershlick AH, Giannuzzi P, Halvorsen S, Huber K, Juni P, Kastrati A, Knuuti J, Lenzen MJ, Mahaffey KW, Valgimigli M, van't Hof A, Widimsky P, Zahger D. ESC guidelines for the management of acute myocardial infarction in patients presenting with ST-segment elevation. Eur Heart J. 2012;33:2569-619.

3. Levine GN, Bates ER, Blankenship JC, Bailey SR, Bittl JA, Cercek B, Chambers CE, Ellis SG, Guyton RA, Hollenberg SM, Khot UN, Lange RA, Mauri L, Mehran R, Moussa ID, Mukherjee D, Nallamothu BK, Ting HH. 2011 ACCF/AHA/SCAI guideline for percutaneous coronary intervention: a report of the American College of Cardiology Foundation/American Heart Association Task Force on Practice Guidelines and the Society for Cardiovascular Angiography and Interventions. J Am Coll Cardiol. 2011;58(24):e44-122.

4. O'Gara PT, Kushner FG, Ascheim DD, Casey Jr DE, Chung MK, de Lemos JA, Ettinger SM, Fang JC, Fesmire FM, Franklin BA, Granger CB, Krumholz HM, Linderbaum JA, Morrow DA, Newby LK, Ornato JP, Ou N, Radford MJ, TamisHolland JE, Tommaso CL, Tracy CM, Woo YJ, Zhao DX, Anderson JL, Jacobs AK, Halperin JL, Albert NM, Brindis RG, Creager MA, DeMets D, Guyton RA, Hochman JS, Kovacs RJ, Ohman EM, Stevenson WG, Yancy CW. 2013 ACCF/AHA guideline for the management of ST-elevation myocardial infarction: a report of the American College of Cardiology Foundation/American Heart Association Task Force on Practice Guidelines. Circulation. 2013;127(4):e362-425.

5. Windecker S, Kolh P, Alfonso F, Collet JP, Cremer J, Falk V, Filippatos G, Hamm C, Head SJ, Juani P, Kappetein AP, Kastrati A, Knuuti J, Landmesser U, Laufer G, Neumann FJ, Richter DJ, Schauerte P, Uva MS, Stefanini GG, Taggart DP, Torracca L, Valgimigli M, Wijns W, Witkowski A. 2014 ESC/EACTS Guidelines on myocardial revascularization: The Task Force on Myocardial Revascularization of the European Society of Cardiology (ESC) and the European Association for Cardio-Thoracic Surgery (EACTS)Developed with the special contribution of the European Association of Percutaneous Cardiovascular Interventions (EAPCI). Eur Heart J. 2014;35(37):2541-619.

6. Srimahachota S, Boonyaratavej $S$, Kanjanavanit R, Sritara P, Krittayaphong R, Kunjara-Na-ayudhya R, Tatsanavivat P, TRACS Group. Thai Registry in Acute Coronary Syndrome (TRACS)-An Extension of Thai Acute Coronary Syndrome Registry (TACS) Group: Lower In-hospital but still high mortality at one-year. J Med Assoc Thai. 2012;95(4):508-18.

7. The GRACE Investigators. Rationale and design of the GRACE (Global Registry of Acute Coronary Events) project: a multinational registry of patients hospitalized with acute coronary syndromes. Am Heart J. 2001;141:190-9.

8. Eagle KA, Lim MJ, Dabbous OH, GRACE Investigators, et al. A validated prediction model for all forms of acute coronary syndromes in an international registry. JAMA. 2004;291:2727-33.

9. Granger CB, Goldberg RJ, Dabbous O, Pieper KS, Eagle KA, Cannon CP, Van de Werf F, Avezum A, Goodman SG, Flather MD, Fox KAA, for the GRACE Investigators. Predictors of hospital mortality in the global registry of acute coronary events. Arch Intern Med. 2003;163:2345-53.

10. Fox KAA, Carruthers KF, Dunba DR, Graham C, Manning JR, Raedt HD, Buysschaert I, Lambrechts D, Van de Werf F. Underestimated and underrecognized: the late consequences of acute coronary syndrome (GRACE UK-Belgian study). Eur Heart J. 2010;31:2755-64.

11. Tang EW, Wong CK, Herbison P. Global Registry of Acute Coronary Events (GRACE) hospital discharge risk score accurately predicts long term mortality post acute coronary syndrome. Am Heart J. 2007;153(1):29-35.

12. Ascenzo FD, Biondi-Zoccai $G$, Moretti $C$, Bollati M, Omedè $P$, Sciuto F, Presutti DG, Modena MG, Gasparini M, Reed MJ, Sheiban I, Gaita F. TIMI, GRACE and alternative risk scores in acute coronary syndromes: a metaanalysis of 40 derivation studies on 216,552 patients and of 42 validation studies on 31,625 patients. Contemp Clin Trials. 2012:33:507-14.

13. Elbarouni B, Goodman SG, Yan RT, Welsh RC, Kornder JM, Deyoung JP, et al. Validation of the Global Registry of Acute Coronary Event (GRACE) risk score for in-hospital mortality in patients with acute coronary syndrome in Canada. Canadian Global Registry of Acute Coronary Events (GRACE/GRACE (2)) investigators. Am Heart J. 2009;158:392-9. 
14. Yan AT, Yan RT, Cantor WJ, Borgundvaag B, Cohen EA, Fitchett DH, Dzavik V, Ducas J, Tan M, Casanova A, Goodman SG, for the TRANSFER-AMI Investigators. Relationship between risk stratification at admission and treatment effects of early invasive management following fibrinolysis: insights from the Trial of Routine ANgioplasty and Stenting after Fibrinolysis to Enhance Reperfusion in Acute Myocardial Infarction (TRANSFER-AMI). Eur Heart J. 2011;32:1994-2002.

15. Borgia F, Goodman SG, Halvorsen S, Cantor WJ, Piscione F, Le May MR, Fernandez-Aviles F, Sanchez PL, Dimopoulos K, Scheller B, Armstrong PW, Di Mario $C$. Early routine percutaneous coronary intervention after fibrinolysis vs. standard therapy in ST-segment elevation myocardial infarction: a metaanalysis. Eur Heart J. 2010;31:2156-69.

16. D'Souza SP, Mamas MA, Fraser DG, Fath-Ordoubadi F. Routine early coronary angioplasty vs. ischaemia-guided angioplasty after thrombolysis in acute STelevation myocardial infarction: a meta-analysis. Eur Heart J. 2011;32(8):972-82.

17. Scheller B, Hennen B, Hammer B, Walle J, Hofer C, Hilpert V, Winter H, Nickenig G, Böhm M, SIAM III Study Group. Beneficial effects of immediate stenting after thrombolysis in acute myocardial infarction. J Am Coll Cardiol. 2003;42:634-41.

18. Cantor WJ, Fitchett D, Borgundvaag B, Ducas J, Heffernan M, Cohen EA, Morrison L, Langer A, Dzavik V, Mehta SR, Lazzam C, Schwartz B, Casanova A, Goodman SG, TRANSFER-AMI Trial Investigators. Routine early angioplasty after fibrinolysis for acute myocardial infarction. N Engl J Med. 2009;360:2705-18.

19. Bohmer E, Hoffmann P, Abdelnoor M, Arnesen H, Halvorsen S. Efficacy and safety of immediate angioplasty versus ischemia-guided management after thrombolysis in acute myocardial infarction in areas with very long transfer distances results of the NORDISTEMI (NORwegian study on Dlstrict treatment of ST-elevation myocardial infarction). J Am Coll Cardiol. 2010;55:102-10.

20. Di Mario C, Dudek D, Piscione F, Mielecki W, Savonitto S, Murena E, Dimopoulos K, Manari A, Gaspardone A, Ochala A, Zmudka K, Bolognese L, Steg PG, Flather M, CARESS-in-AMI (Combined Abciximab RE-teplase Stent Study in Acute Myocardial Infarction) Investigators. Immediate angioplasty versus standard therapy with rescue angioplasty after thrombolysis in the combined Abciximab REteplase Stent Study in Acute Myocardial Infarction (CARESS-in-AMI): an open, prospective, randomised, multicentre trial. Lancet. 2008;371:559-68.

21. Clever YP, Cremers B, Link A, Böhm M, Scheller B. Long-term follow-up of early versus delayed invasive approach after fibrinolysis in acute myocardial infarction. Circ Cardiovasc Interv. 2011:4:342-8.

22. Moretti C, Ascenzo FD, Quadri G, Omedè P, Montefusco A, Taha S, Cerrato E, Colaci C, Chen SL, Biondi-Zoccai G, Gaita F. Management of multivessel coronary disease in STEMI patients: a systematic review and meta-analysis. Int J Cardiol. 2015;179:552-7.

\section{Submit your next manuscript to BioMed Central and we will help you at every step:}

- We accept pre-submission inquiries

- Our selector tool helps you to find the most relevant journal

- We provide round the clock customer support

- Convenient online submission

- Thorough peer review

- Inclusion in PubMed and all major indexing services

- Maximum visibility for your research

Submit your manuscript at www.biomedcentral.com/submit

C) Biomed Central 